\title{
Pathological complete response to mFOLFOX6 plus cetuximab therapy for unresectable colon cancer with multiple paraaortic lymph node metastases
}

\author{
TOMONARI SUETSUGU, NOBUHISA MATSUHASHI, TAKAO TAKAHASHI, TOSHIYUKI TANAHASHI, \\ SATOSHI MATSUI, HISASHI IMAI, YOSHIHIRO TANAKA, KAZUYA YAMAGUCHI and KAZUHIRO YOSHIDA \\ Department of Surgical Oncology, Gifu University School of Medicine, Gifu, Gifu 501-1194, Japan
}

Received August 28, 2018; Accepted October 5, 2018

DOI: $10.3892 / \mathrm{mco} .2018 .1742$

\begin{abstract}
Pathological complete response is achievable with mFOLFOX6 plus cetuximab therapy for unresectable colorectal cancer with multiple paraaortic lymph node metastases (mCRC) despite right-sided colonic origin. A 62-year-old woman with synchronous paraaortic lymph node metastases of transverse colon cancer was treated with mFOLFOX6 plus cetuximab as first-line therapy. The tumor size was markedly decreased following 6 courses of chemotherapy, and all lymph node metastases had disappeared. The patient then underwent conventional right hemicolectomy with D3 lymph node dissection plus sampling excision of the paraaortic lymph nodes. The pathological diagnosis was a complete response. The patient is currently alive 5 years after surgery with no signs of recurrence. The present study reported the apparent effectiveness of conversion therapy (surgery) with combination treatment with mFOLFOX6 plus cetuximab and radical surgery. We hypothesized that patients with different types of mCRC of right-sided colon origin may be effectively treated with anti-EGFR monoclonal antibodies.
\end{abstract}

\section{Introduction}

Recently, chemotherapy for colorectal cancer has progressed markedly. In particular, treatment for unresectable metastatic colorectal cancer (mCRC) has notably improved with

Correspondence to: Dr Nobuhisa Matsuhashi, Department of Surgical Oncology, Gifu University School of Medicine, 1-1 Yanagido, Gifu, Gifu 501-1194, Japan

E-mail: nobuhisa517@hotmail.com

Abbreviations: CT, computed tomography; EGFR, epidermal growth factor receptor; FDG, fluorine-18 fluorodeoxyglucose; $\mathrm{mCRC}$, metastatic colorectal cancer; MSI, microsatellite instability; OS, overall survival; VEGF, vascular endothelial growth factor

Key words: pathological complete response, colon cancer, neoadjuvant chemotherapy, conversion surgery the development of FOLFOX and FOLFIRI therapies (1). Furthermore, combination of monoclonal antibody therapies, including anti-epidermal growth factor receptor (EGFR) monoclonal antibody or anti-vascular endothelial growth factor (VEGF) monoclonal antibody therapy with chemotherapeutic cytotoxic drugs has made treatment more effective and useful for patients with unresectable mCRC (2-6). However, curing unresectable $\mathrm{mCRC}$ is difficult with chemotherapy alone. At present, effective novel chemotherapeutic agents may now convert unresectable $\mathrm{mCRC}$ with liver metastases into resectable disease (conversion therapy) (7).

\section{Case report}

A 62-year-old female with occult blood in her stool was referred to Gifu University Hospital (Gifu, Japan) for evaluation and treatment. The patient had a previous history of appendectomy and cesarean section. Colonoscopy revealed a superficial elevated tumor in the transverse colon (Fig. 1), and biopsy results indicated adenocarcinoma. An abdominal computed tomography (CT) scan revealed increased transverse colon wall thickness and swollen lymph nodes in the mesocolon, and along the superior mesenteric artery and aorta. A fluorine-18 fluorodeoxyglucose (FDG) positron emission tomography scan revealed FDG accumulations in the primary lesion and multiple swollen lymph nodes (Fig. 2). The laboratory data revealed high levels of tumor markers, CEA $(1.5 \mathrm{ng} / \mathrm{ml})$ and CA19-9 $(221.4 \mathrm{U} / \mathrm{ml})$. The initial diagnosis was Stage IVA [T3 N2b M1a (lymph nodes)] according to the Union for international cancer control TNM classification of malignant tumors (8th edition) (8). Colonic stenosis in this patient was not severe; therefore, chemotherapy without surgery was planned for this unresectable case. The first course consisted only of mFOLFOX6 [1-leucovorin $200 \mathrm{mg} / \mathrm{m}^{2}$ administered simultaneously with oxaliplatin $85 \mathrm{mg} / \mathrm{m}^{2}$, followed by a $400-\mathrm{mg} / \mathrm{m}^{2}$ bolus of fluorouracil $(5-\mathrm{FU})$ on day 1 and then $2,400 \mathrm{mg} / \mathrm{m}^{2} 5-\mathrm{FU}$ as an intravenous infusion over $46 \mathrm{~h}$, every 2 weeks], but the tumor marker levels increased markedly. As a genetic analysis revealed presence of the wild-type KRAS gene, mFOLFOX6 plus cetuximab (400 $\mathrm{mg} / \mathrm{m}^{2}$ loading dose on day 1 and then $250 \mathrm{mg} / \mathrm{m}^{2}$ weekly) were administered for the second course. After 6 courses of chemotherapy were performed, the tumor marker levels had declined markedly, and all lymph node 

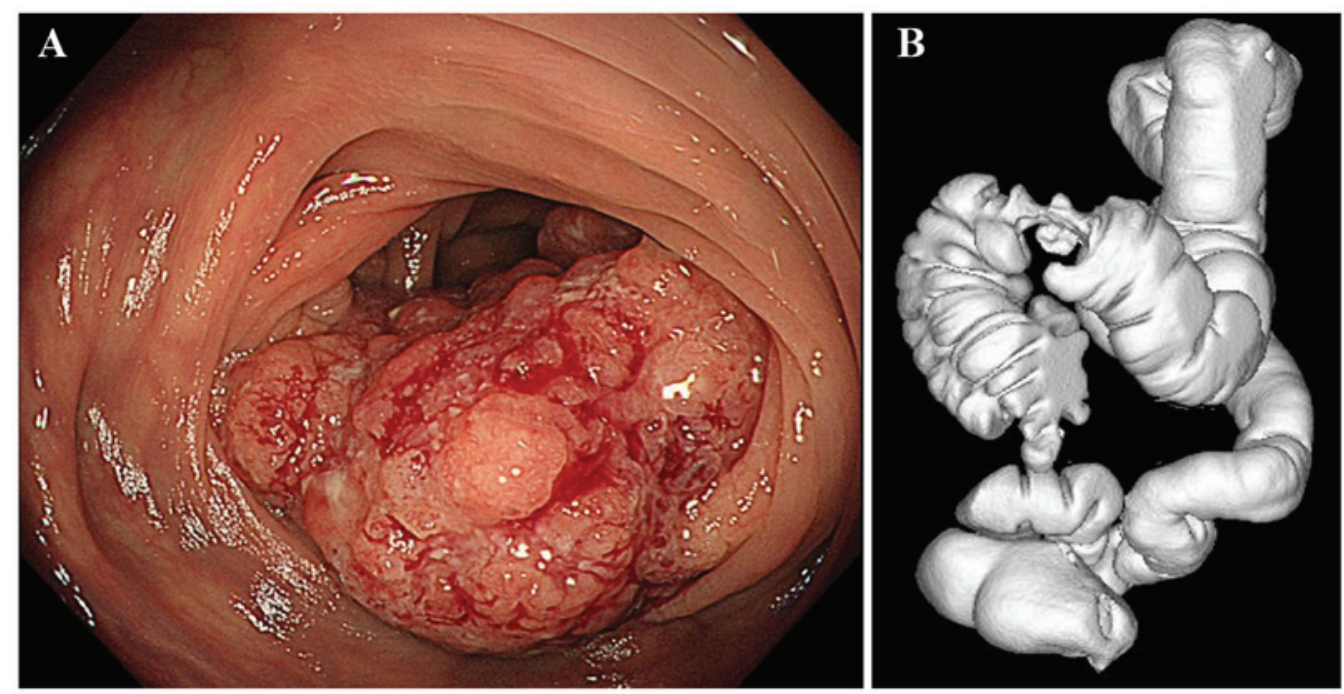

Figure 1. (A) Colonoscopy imaging shows hemicircular superficial elevated tumor. (B) CT colonography shows apple core sign in transverse colon as primary.

metastases had disappeared on enhanced CT scanning, which indicated clinical complete response according to the Response Evaluation Criteria in Solid Tumors (Fig. 3). Therefore, a conventional right hemicolectomy with D3 lymph node dissection plus sampling excision of the paraaortic lymph nodes was performed. The operative specimen was fixed in $10 \%$ buffered formalin for $24 \mathrm{~h}$, then processed to paraffin embedded tissue. Paraffin sections were cut to $4 \mu \mathrm{m}$ in thickness. Sections were deparaffinized by xylene followed by hydrolyzed with ethanol solution series. Antigen retrieval was performed by heating in antigen retrieval solution (Ventana Medical Systems, Inc., Tucson, AZ, USA) at $95^{\circ} \mathrm{C}$ for $35 \mathrm{~min}$. Histological examination of the specimen did not reveal any malignant cells in the colon wall or in the mesocolon lymph nodes (Fig. 4). The pathological diagnosis was a complete response. The patient is currently alive 5 years after surgery with no signs of recurrence.

\section{Discussion}

The prognosis of mCRC has significantly improved in recent years with the development of more effective surgical approaches, and more efficacious chemotherapy regimens, including FOLFOX or FOLFIRI rendering more patients as surgical candidates (9). Chemotherapy is now able to convert unresectable colorectal liver metastasis into resectable disease (conversion chemotherapy), and prior 'rules of resectability' are being challenged (10). This has increased the rates of resectability from $10-15 \%$ to up to $20-30 \%$ with 5- and 10 -year overall survival (OS) rates of $\sim 33$ and $23 \%$, respectively. For example, patients who undergo liver resection and survive beyond 10 years appear to be cured in almost all cases (11). In addition, CRC patients with lung metastases or paraaortic lymph node metastases who undergo radical resection are expected to have improved survival (12-16). The concepts of early tumor shrinkage and deepness of response were also previously assessed in first-line trials with anti-EGFR monoclonal antibodies for patients with KRAS wild-type mCRC $(17,18)$. Therefore, we hypothesized that anti-EGFR monoclonal antibodies are key drugs for the conversion of

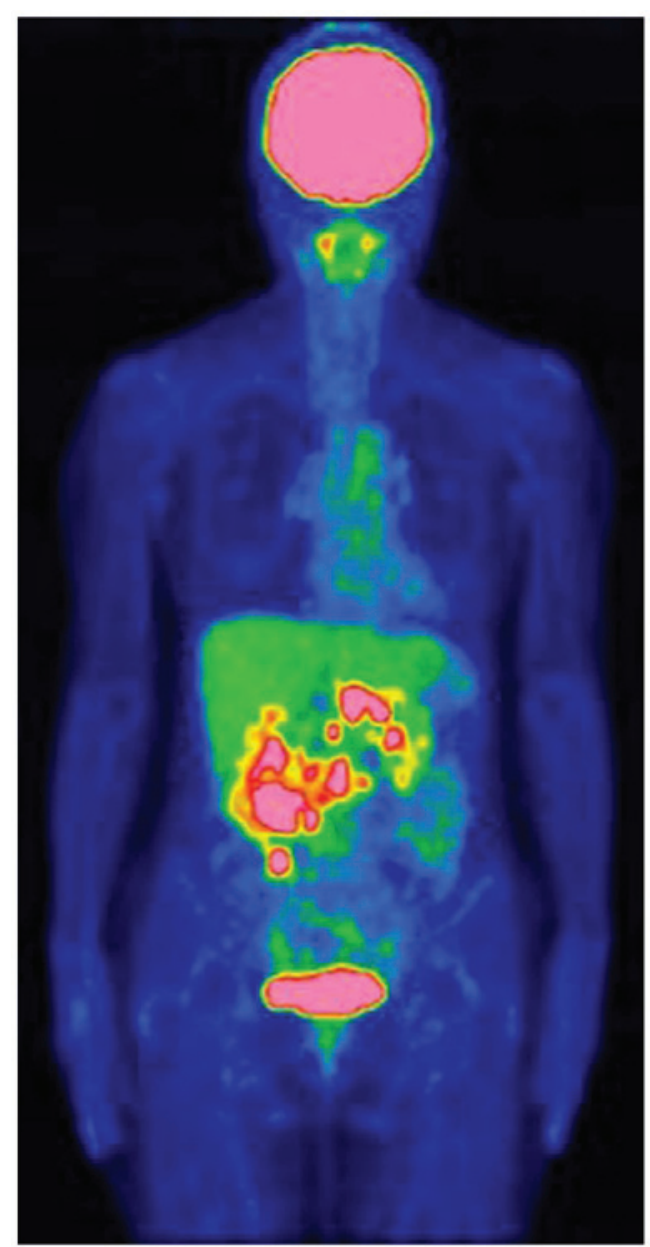

Figure 2. Positron emission tomography-computed tomography demonstrating primary lesion and multiple lymph node metastases.

unresectable and metastatic colorectal metastasis into resectable disease.

Recently, primary tumor location, whether of right- or left-sided origin, has been investigated for its role in aiding in predicting outcomes. OS following anti-EGFR monoclonal 


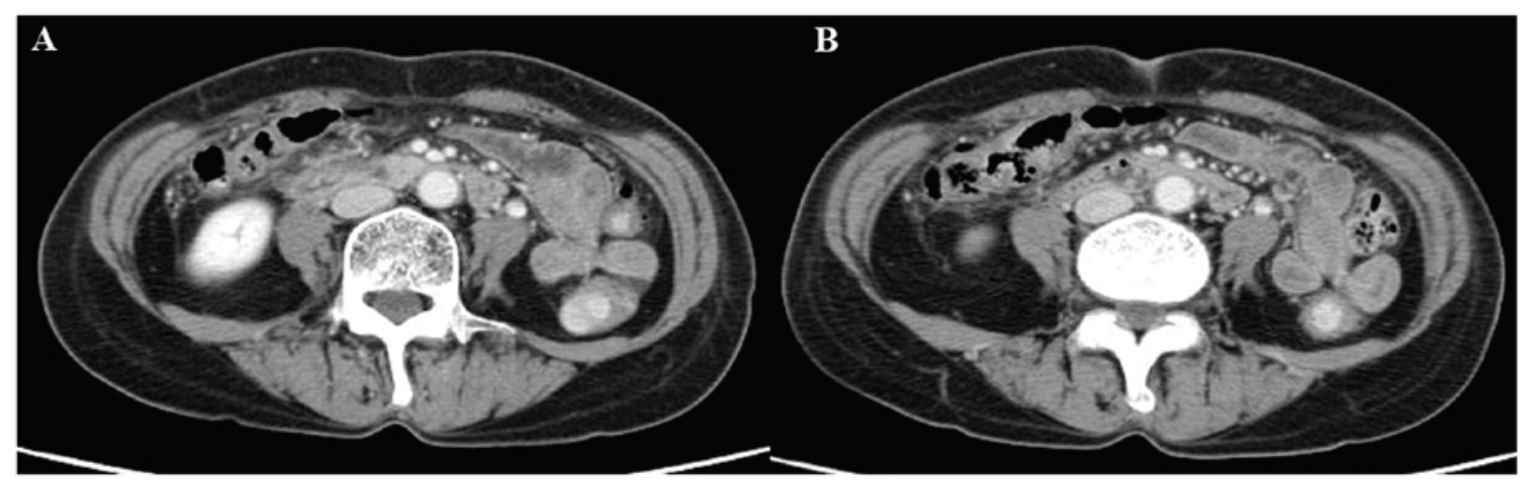

Figure 3. (A) CT at first visit shows multiple paraaortic lymph node metastases with contrast effect. (B) Paraaortic lymph node metastases disappeared following 6 courses of chemotherapy.

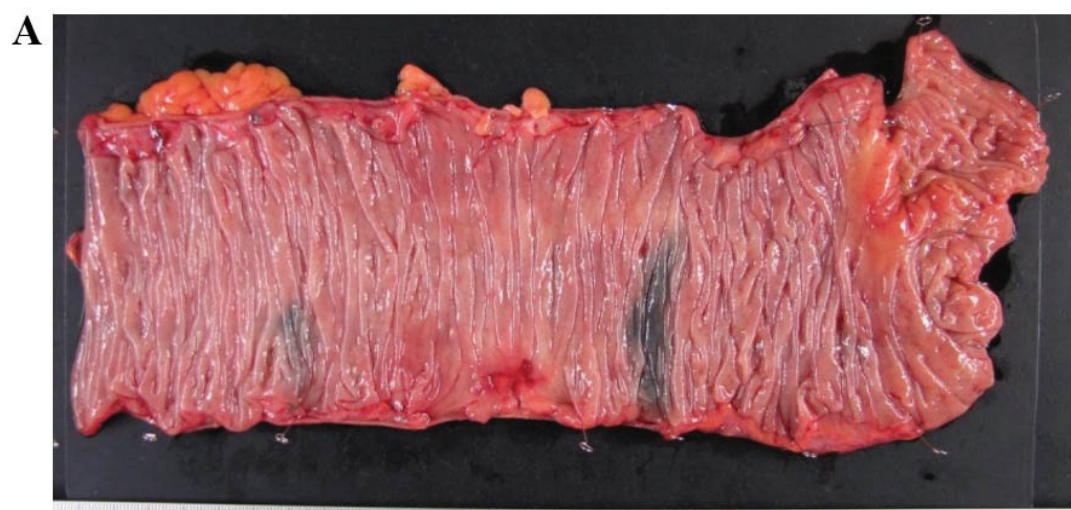

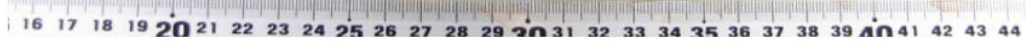
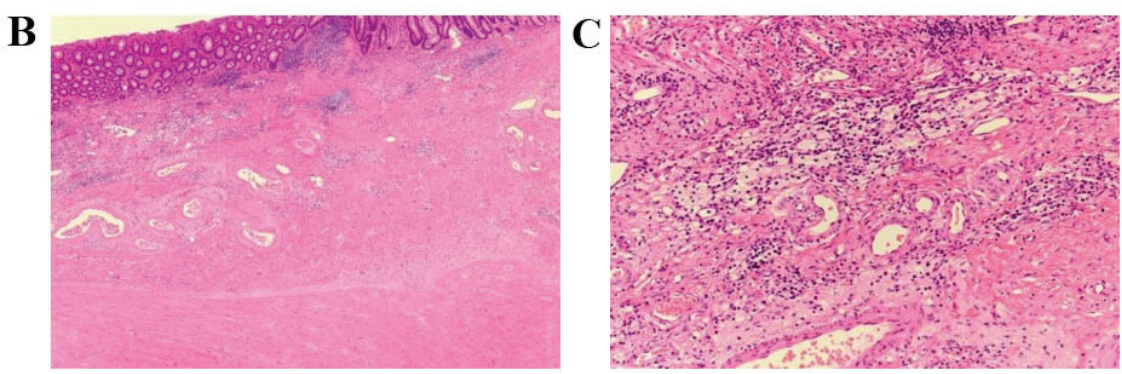

Figure 4. Operative specimen and histological profile of the primary tumor. (A) Primary lesion has almost disappeared following 6 courses of chemotherapy. (B) Low power view of section from operative specimen, showing the absence of tumor cells and the presence of fibrous tissue with the partially collected foamy histiocytes. (Hematoxylin and eosin staining; original magnification, x40). (C) Higher magnification from the fibrotic area showing fibroblasts laying down collagen and a scattering of inflammatory cells (Hematoxylin and eosin staining; original magnification, x100).

antibody treatment with CALGB/SWOG80405 (19) was significantly different between right- and left-sided origins. In particular, OS with anti-EGFR monoclonal antibody treatment was significantly poorer for right-sided origins and significantly improved for left-sided origins. However, Holch et al (20) reported a meta-analysis of OS and progression-free survival of patients with unresectable mCRC treated with CALGB/SWOG80405, FIRE-3 or PEAK $(19,21,22)$. In a comparison of anti-EGFR and anti-VEGF therapy, patients with RAS wild-type left-sided origins received a markedly greater benefit from anti-EGFR-based therapy. These aforementioned studies $(19,21,22)$ also reported the analysis of overall response rates in terms of the impact of primary tumor location on therapy with either anti-EGFR or anti-VEGF antibodies combined with standard chemotherapy. The results demonstrated a significantly improved overall response rate with anti-EGFR monoclonal antibody treatment for tumors of right-sided origins. These results also indicated that BRAF mutant, microsatellite instability (MSI)-high, and $\mathrm{CpG}$ island methylator phenotype-1 tumors are expected to occur more frequently in colon cancer of right-sided origin. In the present case, the treatment regimen of mFOLFOX6 plus cetuximab was effective despite the right-sided origin of the colon cancer.

Therefore, combination chemotherapy and surgical resection may potentially cure transverse colon cancer with multiple paraaortic lymph node metastases. It is important to evaluate the rate of tumor shrinkage from the beginning of the first-line treatment until 6 courses of anti-EGFR monoclonal antibody have been administered and to determine whether conversion therapy (surgery) is possible (23). We hypothesized that patients with different types of $\mathrm{mCRC}$ of right-sided origin may be effectively treated with anti-EGFR monoclonal 
antibodies. At present, patients with poor clinical outcomes can be expected to receive another treatment regimen of antiVEGF monoclonal antibodies $(24,25)$.

In conclusion, the regimen of mFOLFOX6 plus cetuximab was effective in treating the patient with $\mathrm{mCRC}$ in the present study, despite its right-sided origin. We hypothesized that even $\mathrm{mCRC}$ of right-sided origin may be effectively treated with anti-EGFR monoclonal antibody treatment at uniform rates. Anti-PDL-1 antibody treatment is recommended for patients with MSI-high tumors in the National Comprehensive Cancer Network and European Society for Medical Oncology guidelines $(26,27)$. Therefore, not only Ras- and BRAF-type colorectal tumors, but also tumors of every genomic type, may be treated in this manner in the future.

\section{Acknowledgements}

The authors would like to thank Natsuko Suzui and Tatsuhiko Miyazaki of the Pathology Division of Gifu University Hospital for providing assistance with the preparation of the manuscript.

\section{Funding}

Funding information is not applicable.

\section{Availability of data and material}

All data generated or analyzed during this study are included in this published article.

\section{Authors' contributions}

TS and NM were responsible for study conception and design. TS, NM, TTak, TTan, SM, HI, YT and KY were responsible for acquisition of data. TS, NM and TTak were responsible for analysis and interpretation of data. TS and NM were responsible for drafting of the manuscript. TS, NM, TTak and KY were responsible for critical revision of the manuscript. KY was responsible for supervision of the study.

\section{Ethics approval and consent to participate}

Written informed consent for participation in the study or use of their tissue was obtained from the participant.

\section{Patient consent for publication}

Written informed consent was obtained from the patient for publication of this case report and accompanying images.

\section{Competing interests}

All authors declare that they have no competing interest.

\section{References}

1. Tournigand C, André T, Achille E, Lledo G, Flesh M, Mery-Mignard D, Quinaux E, Couteau C, Buyse M, Ganem G, et al: FOLFIRI followed by FOLFOX6 or the reverse sequence in advanced colorectal cancer: A randomized GERCOR study. J Clin Oncol 22: 229-237, 2004.
2. Hurwitz H, Fehrenbacher L, Novotny W, Cartwright T, Hainsworth J, Heim W, Berlin J, Baron A, Griffing S, Holmgren E, et al: Bevacizumab plus irinotecan, fluorouracil, and leucovorin for metastatic colorectal cancer. N Engl J Med 350: 2335-2342, 2004.

3. Saltz LB, Clarke S, Díaz-Rubio E, Scheithauer W, Figer A, Wong R, Koski S, Lichinitser M, Yang TS, Rivera F, et al: Bevacizumab in combination with oxaliplatin-based chemotherapy as first-line therapy in metastatic colorectal cancer: A randomized phase III study. J Clin Oncol 26: 2013-2019, 2008.

4. De Roock W, Jonker DJ, Di Nicolantonio F, Sartore-Bianchi A, Tu D, Siena S, Lamba S, Arena S, Frattini M, Piessevaux H, et al: Association of KRAS p.G13D mutation with outcome in patients with chemotherapy-refractory metastatic colorectal cancer treated with cetuximab. JAMA 304: 1812-1820, 2010.

5. Van Cutsem E, Köhne CH, Láng I, Folprecht G, Nowacki MP, Cascinu S, Shchepotin I, Maurel J, Cunningham D, Tejpar S, et al: Cetuximab plus irinotecan, fluorouracil, and leucovorin as first-line treatment for metastatic colorectal cancer: Updated analysis of overall survival according to tumor KRAS and BRAF mutation status. J Clin Oncol 29: 2011-2019, 2011.

6. Douillard JY, Oliner KS, Siena S, Tabernero J, Burkes R, Barugel M, Humblet Y, Bodoky G, Cunningham D, Jassem J, et al: Panitumumab-FOLFOX4 treatment and RAS mutations in colorectal cancer. N Engl J Med 369: 1023-1034, 2013.

7. Folprecht G, Gruenberger T, Bechstein W, Raab HR, Weitz J, Lordick F, Hartmann JT, Stoehlmacher-Williams J, Lang H, Trarbach T, et al: Survival of patients with initially unresectable colorectal liver metastases treated with FOLFOX/cetuximab or FOLFIRI/cetuximab in a multidisciplinary concept (CELIM study). Ann Oncol 25: 1018-1025, 2014.

8. Brierley JD, Gospodarowicz MK and Wittekind C: TNM Classification of Malignant Tumours. 8th edition. Wiley -Blackwell, London, 2017

9. Kopetz S, Chang GJ, Overman MJ, Eng C, Sargent DJ, Larson DW, Grothey A, Vauthey JN, Nagorney DM and McWilliams RR: Improved survival in metastatic colorectal cancer is associated with adoption of hepatic resection and improved chemotherapy. J Clin Oncol 27: 3677-3683, 2009.

10. Adam R, Delvart V, Pascal G, Valeanu A, Castaing D, Azoulay D, Giacchetti S, Paule B, Kunstlinger F, Ghémard O, et al: Rescue surgery for unresectable colorectal liver metastases downstaged by chemotherapy: A model to predict long-term survival. Ann Surg 240: 644-657, discussion 657-658, 2004.

11. Tomlinson JS, Jarnagin WR, DeMatteo RP, Fong Y, Kornprat P, Gonen M, Kemeny N, Brennan MF, Blumgart LH and D'Angelica M: Actual 10-year survival after resection of colorectal liver metastases defines cure. J Clin Oncol 25: 4575-4580, 2007.

12. Yedibela S, Klein P, Feuchter K, Hoffmann M, Meyer T, Papadopoulos T, Göhl J and Hohenberger W: Surgical management of pulmonary metastases from colorectal cancer in 153 patients. Ann Surg Oncol 13: 1538-1544, 2006.

13. Iida T, Nomori H, Shiba M, Nakajima J, Okumura S, Horio H, Matsuguma H, Ikeda N, Yoshino I, Ozeki Y, et al; Metastatic Lung Tumor Study Group of Japan: Prognostic factors after pulmonary metastasectomy for colorectal cancer and rationale for determining surgical indications: A retrospective analysis. Ann Surg 257: 1059-1064, 2013.

14. Min BS, Kim NK, Sohn SK, Cho CH, Lee KY and Baik SH: Isolated paraaortic lymph-node recurrence after the curative resection of colorectal carcinoma. J Surg Oncol 97: 136-140, 2008.

15. Choi PW, Kim HC, Kim AY, Jung SH, Yu CS and Kim JC: Extensive lymphadenectomy in colorectal cancer with isolated para-aortic lymph node metastasis below the level of renal vessels. J Surg Oncol 101: 66-71, 2010.

16. Nakai N, Yamaguchi T, Kinugasa Y, Shiomi A, Kagawa H, Yamakawa Y, Numata M and Furutani A: Long-term outcomes after resection of para-aortic lymph node metastasis from leftsided colon and rectal cancer. Int J Colorectal Dis 32: 999-1007, 2017.

17. Tsuji A, Sunakawa Y, Ichikawa W, Nakamura M, Kochi M, Denda T, Yamaguchi T, Shimada K, Takagane A, Tani S, et al: Early tumor shrinkage and depth of response as predictors of favorable treatment outcomes in patients with metastatic colorectal cancer treated with FOLFOX plus cetuximab (JACCRO CC-05). Target Oncol 11: 799-806, 2016.

18. Ye LC, Wei Y, Zhu DX, Chen T and Xu J: Impact of early tumor shrinkage on clinical outcome in wild-type-KRAS colorectal liver metastases treated with cetuximab. J Gastroenterol Hepatol 30: 674-679, 2015. 
19. Venook AP, Niedzwiecki D, Lenz HJ, Innocenti F, Fruth B, Meyerhardt JA, Schrag D, Greene C, O'Neil BH, Atkins JN, et al: Effect of first-line chemotherapy combined with cetuximab or bevacizumab on overall survival in patients with KRAS wild-type advanced or metastatic colorectal cancer: A randomized clinical trial. JAMA 317: 2392-2401, 2017.

20. Holch JW, Ricard I, Stintzing S, Modest DP and Heinemann V: The relevance of primary tumour location in patients with metastatic colorectal cancer: A meta-analysis of first-line clinical trials. Eur J Cancer 70: 87-98, 2017.

21. Heinemann V, von Weikersthal LF, Decker T, Kiani A, VehlingKaiser U, Al-Batran S-E et al: FOLFIRI plus cetuximab versus FOLFIRI plus bevacizumab as first-line treatment for patients with metastatic colorectal cancer (FIRE-3): a randomised, openlabel, phase 3 trial. Lancet Oncol 15:1065-1075, 2014

22. Schwartzberg LS, Rivera F, Karthaus M, Fasola G, Canon JL, Hecht JR, et al: PEAK: a randomized, multicenter phase II study of panitumumab plus modified fluorouracil, leucovorin, and oxaliplatin (mFOLFOX6) or bevacizumab plus mFOLFOX6 in patients with previously untreated, unresectable, wild-type KRAS exon 2 metastatic colorectal cancer. Journal of clinical oncology: J Clin Oncol 21. 2240-2247, 2014

23. Poston G, Adam R, Xu J, Byrne B, Esser R, Malik H, Wasan H and $\mathrm{Xu}$ J: The role of cetuximab in converting initially unresectable colorectal cancer liver metastases for resection. Eur J Surg Oncol 43: 2001-2011, 2017.
24. Cremolini C, Loupakis F, Antoniotti C, Lonardi S, Masi G, Salvatore L, Cortesi E, Tomasello G, Spadi R, Zaniboni A, et al: Early tumor shrinkage and depth of response predict long-term outcome in metastatic colorectal cancer patients treated with first-line chemotherapy plus bevacizumab: Results from phase III TRIBE trial by the Gruppo Oncologico del Nord Ovest. Ann Oncol 26: 1188-1194, 2015.

25. Tomasello G, Petrelli F, Ghidini M, Russo A, Passalacqua R and Barni S: FOLFOXIRI plus bevacizumab as conversion therapy for patients with initially unresectable metastatic colorectal cancer: A systematic review and pooled analysis. JAMA Oncol 3: e170278, 2017.

26. NCCN: National Cancer Guidelines for Patients: Colon Cancer. https://www.nccn.org/patients/guidelines/colon/. Accessed September 8, 2018.

27. Van Cutsem E, Cervantes A, Adam R, Sobrero A, Van Krieken JH, Aderka D, Aranda Primary lesion has almost disappeared Aguilar E, Bardelli A, Benson A, Bodoky G, et al: ESMO consensus guidelines for the management of patients with metastatic colorectal cancer. Ann Oncol 27: 1386-1422, 2016.

This work is licensed under a Creative Commons Attribution-NonCommercial-NoDerivatives 4.0 International (CC BY-NC-ND 4.0) License. 